\title{
Enhanced laser thermal ablation for the in vitro treatment of liver cancer by specific delivery of multiwalled carbon nanotubes functionalized with
} human serum albumin

\author{
This article was published in the following Dove Press journal: \\ International Journal of Nanomedicine \\ I3 January 2011 \\ Number of times this article has been viewed
}

\author{
Cornel lancu' \\ Lucian Mocan' \\ Constantin Bele ${ }^{2}$ \\ Anamaria loana Orza ${ }^{2}$ \\ Flaviu A Tabaran ${ }^{3}$ \\ Cornel Catoi ${ }^{3}$ \\ Rares Stiufiuc ${ }^{4}$ \\ Ariana Stirl \\ Cristian Matea ${ }^{2}$ \\ Dana lancu' \\ Lucia Agoston-Coldea' \\ Florin Zaharie' \\ Teodora Mocan' \\ 'Department of Nanomedicine, 'Iuliu \\ Hatieganu' University of Medicine \\ and Pharmacy, Third Surgery Clinic, \\ Cluj-Napoca, Romania; ${ }^{2}$ Department \\ of Biochemistry, ${ }^{3}$ Department of \\ Pathology, Faculty of Veterinary \\ Medicine, University of Agricultural \\ Sciences and Veterinary Medicine, \\ Cluj-Napoca, Romania; ${ }^{4}$ Department \\ of Biophysics, 'Iuliu Hatieganu' \\ University of Medicine and Pharmacy, \\ Cluj-Napoca, Romania
}

Correspondence: Cornel lancu and Lucian Mocan Department of Nanomedicine, 'Iuliu Hatieganu' University of Medicine and Pharmacy, Third Surgery Clinic,

19-2I Croitorilor Street, 400162

Cluj-Napoca, Romania

Tel +40264439696

Fax +40 264439696

Email cornel.iancu@umfcluj.ro;

lucian.mocan@k.ro

\begin{abstract}
The main goal of this investigation was to develop and test a new method of treatment for human hepatocellular carcinoma (HCC). We present a method of carbon nanotube-enhanced laser thermal ablation of HepG2 cells (human hepatocellular liver carcinoma cell line) based on a simple multiwalled carbon nanotube (MWCNT) carrier system, such as human serum albumin (HSA), and demonstrate its selective therapeutic efficacy compared with normal hepatocyte cells. Both HepG2 cells and hepatocytes were treated with HSA-MWCNTs at various concentrations and at various incubation times and further irradiated using a $2 \mathrm{~W}, 808 \mathrm{~nm}$ laser beam. Transmission electron, phase contrast, and confocal microscopy combined with immunochemical staining were used to demonstrate the selective internalization of HSA-MWCNTs via Gp60 receptors and the caveolin-mediated endocytosis inside HepG2 cells. The postirradiation apoptotic rate of HepG2 cells treated with HSA-MWCNTs ranged from $88.24 \%$ (for $50 \mathrm{mg} / \mathrm{L}$ ) at $60 \mathrm{sec}$ to $92.34 \%$ (for $50 \mathrm{mg} / \mathrm{L}$ ) at $30 \mathrm{~min}$. Significantly lower necrotic rates were obtained when human hepatocytes were treated with HSA-MWCNTs in a similar manner. Our results clearly show that HSA-MWCNTs selectively attach on the albondin (aka Gp60) receptor located on the HepG2 membrane, followed by an uptake through a caveolin-dependent endocytosis process. These unique results may represent a major step in liver cancer treatment using nanolocalized thermal ablation by laser heating.
\end{abstract}

Keywords: carbon nanotubes, albumin, HepG2 cells, noncovalent functionalization, laser irradiation, Gp60 receptor

\section{Introduction}

Hepatocellular carcinoma (HCC) represents a leading cause of cancer deaths worldwide. ${ }^{1-3}$ Despite recent discoveries in screening and early detection, HCC exhibits a rapid clinical course with an average survival of 6 months and an overall 5-year survival rate of 5\%. As chemotherapy and radiotherapy show modest results ${ }^{5}$ and surgery is possible in $10 \%-30 \%$ of patients, ${ }^{6,7}$ new therapeutic methods offer hope for a better outcome.

Most data suggest that nanotechnologies could play a major role in the development of new anticancer therapies. A thermal approach using nanoparticles, nanoemulsion, $\mathrm{pH}-$ responsive nanoparticles, nanoparticles combined with radiation, and nanovectors for drug delivery are the most explored nanoparticle-based cancer treatment methods. ${ }^{8}$

The ability of carbon nanotubes (CNTs) to convert near-infrared (NIR) laser radiation into heat, due to the photon-phonon and electron interactions, ${ }^{9}$ provides the 
opportunity to create a new generation of immunoconjugates for cancer phototherapy, with good performance and efficacy in selective cancer thermal ablation, as well as in the application of nanotechnology in molecular diagnostics (nanodiagnostics). ${ }^{8,10}$

Nanotechnology has already shown promising results in HCC research and treatment. Microwave ${ }^{11}$ ablation and radiofrequency ${ }^{12}$ ablation were proposed for the treatment of HCC. Intratumorally administered CNTs combined with laser irradiation proved to be efficient in the treatment of HCC on animal models. ${ }^{13}$ However, a major challenge in treating $\mathrm{HCC}$ is represented by therapies strictly directed toward the tumor cells inside the liver parenchyma. Generally, the use of targeting molecules such as antibodies, folates, and growth factors has been specifically proposed for carrying nanomaterials to the cancer cells and tumors. ${ }^{14-16}$ However, $100 \%$ selective internalization of nanobioconjugates in the cancer cells remains problematic. ${ }^{17}$ This can be explained by the presence of the receptors used for the specific binding of the targeting molecules on the membranes of the noncancerous cells, although in smaller concentrations compared with the cancer cells. ${ }^{18}$

The use of CNTs as bioactive molecules is still at an early research stage, but their unique physical and chemical properties hold great hope for cancer treatment..$^{8,14,16-18}$ Nevertheless, there are many toxicity concerns to be addressed. It has been stated that a proficient method needed to minimize toxic effects and also to increase the level of therapeutic response for CNTs is represented by their conjugation to a carrier molecule. ${ }^{19-23}$ The use of these biological carriers for the development of specific and sensitive site-targeted bionanosystems also allows the selective internalization of CNTs into cancer cells.

Research data have shown that highly proliferative tumors have the capacity to create albumin deposits. ${ }^{24}$ The reports have demonstrated the liver cancer cells' overexpression of specific human serum albumin (HSA) receptors and their ability to internalize large amounts of albumin through the mechanism of caveolae-mediated endocytosis. ${ }^{25}$ The resulting amino acids are further used for the synthesis of various substrates needed for tumor growth. ${ }^{26,27}$ Considering all these data together, we propose a method for the functionalization of multiwalled carbon nanotubes (MWCNTs) with HSA for the selective targeting and laser-mediated necrosis of liver cancer cells. To our knowledge, this is the first demonstration of selective targeting via Gp60 receptors located on the membrane of malignant liver cancer cells using a conjugate of HSA and CNTs.

\section{Material and methods}

\section{Antibodies and reagents}

For the experiments involving the noncovalent functionalization of CNTs, MWCNTs $(>90 \%$ carbon basis, $\mathrm{OD} \times \mathrm{ID} \times \mathrm{L}$ $10-15 \mathrm{~nm} \times 2-6 \mathrm{~nm} \times 0.1-10 \mu \mathrm{m}$, product number 677248$)$, HSA, and Sephacryl 100-HR were purchased from Sigma-Aldrich (Steinheim, Germany), and all the other chemicals were purchased from Merck (Darmstadt, Germany). HepG2 cells and immortalized hepatocyte epithelial cells (CRL-4020) were purchased from ATCC (Rockville, MD, USA), and all the other reagents needed for cell culture were purchased from Sigma-Aldrich. For the experiments involving cell apoptosis, Cell Death Detection ELISA ${ }^{\text {PLUS }}$ was purchased from Roche Applied Science (Mannheim, Germany). For immunostaining procedures, Draq5, 4'-6-diamidino-2-phenylindole (DAPI), and anti-caveolin-1-Cy3 antibody $(\mathrm{Ab})$ produced in rabbit were purchased from Sigma-Aldrich. Polyclonal Gp60 Ab was prepared as previously described, ${ }^{28}$ and for use as a fluorescent probe a cy3 derivative of anti-Gp60 was prepared according to the existing protocol. ${ }^{29}$

\section{Noncovalent functionalization of CNTs with HSA}

A total of $60 \mathrm{mg}$ MWCNTs were dispersed in a 3:1 (v/v) mixture of concentrated sulfuric and nitric acid and sonicated for $3 \times 10 \mathrm{~s}$ with a tip sonicator. Subsequently, the mixture was refluxed at $120^{\circ} \mathrm{C}$ for $30 \mathrm{~min}$. The oxidized MWCNTs treated in water solution were then centrifuged at $8000 \mathrm{rpm}$ to remove any large unreacted CNTs from the solution and metallic impurities. Finally, the oxidized MWCNTs were vacuum filtered through a $0.2-\mu \mathrm{m}$ polycarbonate filter (Whatman) until the elution was clear and at neutral $\mathrm{pH}$. The filter cake was dried overnight at room temperature. After filtration, the solution concentration was re-estimated using UV-Vis-NIR spectroscopy (JASCO V530, Gross-Umstadt, Germany). A total of $1 \mathrm{mg}$ of fluorescein isothiocyanate (FITC) $(10 \mathrm{mg} / \mathrm{mL}$ in dimethyl sulfoxide) was mixed with $50 \mathrm{mg}$ HSA in sodium buffer (20 mM, pH 8.5), followed by incubation for $2 \mathrm{~h}$ in darkness, at room temperature, with continuous stirring. The HSA-FITC conjugate was purified by gel chromatography using a Sephacryl 100-HR column eluted with $10 \mathrm{mM}$ phosphate buffered saline (PBS). ${ }^{30}$

Oxidized MWCNTs and HSA-FITC were mixed with deionized water at a concentration of 0.25 and $1.25 \mathrm{mg} / \mathrm{mL}$, respectively. The mixture was sonicated for $1 \mathrm{~h}$ with a tip sonicator in an ice bath and was then centrifuged for $5 \mathrm{~min}$ at 12,000 rpm. The solid was settled at the bottom of the centrifuge tube and consisted of unbound nanotubes, impurities, metals, and bundles of oxidized nanotubes. 
The resulting supernatant was collected and subjected to a second centrifugation round. The supernatant collected contained the desired MWCNT-HSA conjugate.

For further purification, the supernatant was subjected to a gel chromatography purification process. Sephacryl $100-$ HR that was presoaked and deaerated using a vacuum pump was packed up to $15 \mathrm{~cm}$ in a $2.5 \mathrm{~cm}$ diameter $\times 24 \mathrm{~cm}$ long glass column. The oxidized MWCNT-HSA supernatant recovered after centrifugation was layered on the top of the gel and eluted using water flowing under gravity. Volume fractions were collected for periods of 1 min duration and analyzed for the presence of MWCNTs and HSA by measuring the absorbance at 500 and $280 \mathrm{~nm}$, respectively, using the spectrophotometer (JASCO V530). Fractions showing protein content were pooled for further use.

\section{Preparation of MWCNTs}

The nonconjugated highly purified MWCNT control solution was prepared as previously described..$^{31}$ The solution was diluted in minimum essential medium at a 1:10 (v/v) ratio.

\section{Characterization of MWCNTs bioconjugates}

The morphology of MWCNTs functionalized with HSA was examined using a WITEC alpha 300 Atomic Force Microscope (Ulm, Germany), operating under ambient conditions. The images were collected in tapping mode using a silicon nitride cantilever.

The optical properties of oxidized MWCNTs functionalized with HSA-FITC were monitored using a UV-Vis spectrophotometer (JASCO V570).

Fourier transform infrared (FTIR) measurements were performed with a JASCO 6100 spectrometer in the $4000-500 \mathrm{~cm}^{-1}$ spectral region, with a resolution of $4 \mathrm{~cm}^{-1}$ using the $\mathrm{KBr}$ pellet technique.

\section{Cell culture}

HepG2 and CRL-4020 cells, purchased from the American Type Culture Collection (ATCC) (Manassas, VA, USA), were grown in $25 \mathrm{~cm}^{3}$ Corning plastic plates in minimum essential medium, supplemented with $10 \%$ fetal bovine serum and $1 \%$ penicillin-streptomycin. The cells were maintained in a humidified $5 \% \mathrm{CO}_{2}$ incubator at $37^{\circ} \mathrm{C}$. The cells were kept in the logarithmic growth phase by routine passage every 3-4 days. When reaching confluence, the cells were split after rinsing with PBS and detached with trypsin.

For the experiments, the cells were cultivated to confluence on $60 \mathrm{~mm}$ plates. The MWCNTs functionalized with
HSA were further administered to the cell cultures by adding to the culture medium and incubating for various periods of time ( $1 \mathrm{~min} ; 30 \mathrm{~min} ; 1 \mathrm{~h} ; 5 \mathrm{~h} ; 24 \mathrm{~h}$ ) at increased concentrations: 1, 5, 20, $50 \mathrm{mg} / \mathrm{L}$. For each concentration, all the experiments were performed in triplicate.

\section{Cell characterization}

For the microscopy analysis, the cells were trypsinated and transferred to $35 \mathrm{~mm}$ plates, at a density of $25 \times 10^{4}$ cells/dish. After administration and irradiation, the cells were thoroughly washed with $1 \times$ PBS three times, fixed with $10 \%$ formaldehyde solution for $10 \mathrm{~min}$, washed three times with PBS, and stained with methyl green dye for $10 \mathrm{~min}$. Cells in culture were examined using an Olympus CKX 31 (Munich, Germany) inverted microscope with phase contrast.

\section{Cell viability}

The extent of apoptosis was evaluated using a Cell Death Detection ELISA ${ }^{\text {PLUS }}$ assay kit from Roche Applied Science. The assay is a quantitative sandwich enzyme-linked immunosorbent assay (ELISA) that uses the fact that, due to cellular death, nucleosomes are released from the nucleus into the cytosol. These nucleosomes can be detected by antihistone biotin-labeled Abs. The nucleosome-Abs complex will bind to streptavidin-coated well plate and give a signal at $405 \mathrm{~nm}$ on the addition of substrate. After irradiating the cells that were previously treated with various doses of HSA-MWCNTs, the culture media were removed and briefly centrifuged in order to collect the floating cells. The culture dish was rinsed with PBS, and then $0.25 \%$ trypsin was added to detach the cells. Once detached, the cell suspension was combined with the cells collected from the media. The resulting mixture of the cells was briefly spun to collect the cells. The supernatant was discarded, and the pelleted cells were resuspended in ice-cold PBS. The cell suspension was subjected to the final centrifugation, and the pellet was resuspended in the Roche lysis buffer. After 30 min incubation at room temperature, the reaction mixture was centrifuged at $200 \mathrm{~g}\left(4^{\circ} \mathrm{C}\right)$ for $10 \mathrm{~min}$. The pellet, which contains the nucleus, was removed, and the supernatant, which represents the cytoplasmic fraction, was aliquoted into new tubes and kept frozen at $-80^{\circ} \mathrm{C}$ until use.

This supernatant solution would contain the fragmented nucleosomes if the cells underwent apoptosis. After measuring the protein concentration of the resulting supernatant using bicinchoninic acid (BCA) assay, $20 \mathrm{~g}$ of total protein in $20 \mu \mathrm{L}$ were added to the streptavidin-coated 96-well plate. Twenty microliters of each incubation buffer and DNA-histone complex was used as a background control and positive control, 
respectively. Then, $80 \mu \mathrm{L}$ of immunoreagent was added to each well and incubated for $2 \mathrm{~h}$ at room temperature, with gentle and continuous stirring. After the incubation, the solution in the wells was thoroughly removed using gentle suction and rinsed three times in incubation buffer. Finally, $100 \mu \mathrm{L}$ of 2,2'-azino-bis-(3-ethylbenzthiazoline-6-sulfonic acid) (ABTS) substrate solution was added to each well and incubated until the desired strength of color was achieved, which took about $7 \mathrm{~min}$.

The multiwell plates were then placed into a Labsystem Multiskan Plus Spectrophotometer (Helsinki, Finland). The absorbance was measured at $405 \mathrm{~nm}$, with $495 \mathrm{~nm}$ as the reference wavelength. The absorbance at $495 \mathrm{~nm}$ was deducted from the absorbance at $405 \mathrm{~nm}$ for all samples and controls. Then, the $\mathrm{OD}_{405}-\mathrm{OD}_{495}$ value of the background control, which is composed of the incubation buffer and ABTS solution, was subtracted from all $\mathrm{OD}_{405}-\mathrm{OD}_{495}$ values of the samples. The intensity of apoptosis can be expressed as enrichment factor $=(\mathrm{mU}$ of the sample $) /(\mathrm{mU}$ of the corresponding negative control), where $\mathrm{mU}$ is the absorbance $\times 10^{-3}$ after subtracting the reference absorbance and the $\mathrm{OD}_{405}-\mathrm{OD}_{495}$ value of the background control. The enrichment factor exhibits the specific enrichment of mononucleosomes and oligonucleosomes released into the cytoplasm of the cells that are dying and dead due to apoptosis. Finally, the values were normalized so that the untreated sample could have an enrichment factor equal to $1 .{ }^{32}$

\section{Laser treatment}

We used 2 W of power laser (Apel Laser, Bucharest, Romania) operating at $808 \mathrm{~nm}$ for a 2 minutes irradiation of a monolayer of cells placed on a glass substrate, after being incubated with HSA-MWCNTs for various periods of time. The laser diode was placed $3 \mathrm{~cm}$ away from the surface of the glass, at a vertical angle, and the beam had a Gaussian distribution with a $1 / e^{2}$ value of $2 \mathrm{~mm}$.

\section{Laser confocal microscopy of cells}

Fluorescent images were acquired using a Zeiss LSM 710 confocal laser scanning unit (Oberkochen, Germany) equipped with argon and an HeNe laser mounted on an Axio Observer Z1 Inverted Microscope. Hep2G cells or human hepatocytes from the suspension were briefly rinsed with PBS and fixed in 4\% formaldehyde ( $\mathrm{pH} 7$ ) for $15 \mathrm{~min}$. After three washing procedures in PBS for $15 \mathrm{~min}$, the slides were covered for 60 min with a serum-free blocking buffer (Dako Cytomation, Glostrup, Denmark). The dying procedures were made in accordance with manufacturers' protocols. Specific visualization of cell structures was performed using 364 , 488, and $568 \mathrm{~nm}$ excitation laser lines to detect Draq5 (BP 590-650 nm emission), DAPI (BP 385-470 nm emission), FITC (BP505-550 emission), and cy3 fluorescence (LP585 emission), respectively.

\section{Transmission electron microscopy analysis}

The internalization of the functionalized nanotubes was investigated using transmission electron microscopy (TEM) in conventional electron beam conditions. Live cells were incubated in an HSA-MWCNT solution as described previously. After the final PBS rinsing, the cells were fixed using $2.5 \%$ glutaraldehyde in $0.1 \mathrm{M}$ cacodylate buffer and embedded in agarose. After three rinses with sodium phosphate buffer, the monolayers were sectioned into small pieces, postfixed with $1 \%$ osmium tetroxide, en bloc stained with $1 \%$ uranyl acetate, dehydrated in graded ethanol series (30\%, 50\%, 75\%, 100\%, $10 \mathrm{~min}$ each), and embedded in EMbed 812 resin. Ultrathin $(\sim 100 \mathrm{~nm})$ sections were cut on an LEICA EM UC6 Ultramicrotome (Leica Microsystems, Wetzlar, Germany), poststained with 4\% uranyl acetate and lead citrate, and viewed using a Jeol JEM 1010 TEM (Jeol, Tokyo, Japan). The images were captured using a Mega VIEW III camera (Olympus, Soft Imaging System, Münster, Germany).

\section{Statistical data analysis}

All data were expressed as mean \pm standard error of the mean. Nonparametric tests were selected due to data nonnormality (Kolmogorov-Smirnov test). Between-group comparisons for the same concentration were tested using the Wilcoxon test. Alpha error level of $<0.05$ was selected for all tests. SPSS Statistics Version 17.0 (Chicago, IL, USA) packages, as well as the Microsoft Office Excel application, were used for data analysis.

\section{Results}

\section{Functionalization of MWCNTs with HSA}

In order to obtain a directly targeted delivery of MWCNTs into the cancer cells and to visualize and detect the localization of the nanotubes inside the cell, the FITC-HSA system was preformed and noncovalently labeled on the oxidized surface of MWCNTs.

To provide clues regarding the success of noncovalent HSA-MWCNT functionalization, confocal microscopy was proposed for the identification of FITC-labeled CNTs in solution. As shown in Figure IC, globular green 
CNTs corresponding to large molecules of fluorescent albumin were observed.

The oxidation of the nanotubes using a 3:1 (v/v) mixture of concentrated sulfuric and nitric acid gave them hydrophilicity and stability in aqueous systems due to the formation of $-\mathrm{COOH}, \mathrm{OH}$ groups at the end and along the sidewalls of the tubes. ${ }^{21}$

FTIR spectra from Figure 2A confirm successful oxidation. Comparing the FTIR spectra of pristine MWCNTs (black) with those of oxidized MWCNTs (red), the characteristic bands of the oxygen-containing groups appear at $3422 \mathrm{~cm}^{-1}$, corresponding to the stretching vibration of $\mathrm{O}-\mathrm{H}$ and water, ${ }^{33}$ a band at $1721 \mathrm{~cm}^{-1}$, corresponding to the carbonyl and carboxyl $\mathrm{C}=\mathrm{O}$ stretching vibration, at 1582 and $1380 \mathrm{~cm}^{-1}$, corresponding to the $\mathrm{O}-\mathrm{H}$ deformation vibration, and the band at $1117 \mathrm{~cm}^{-1}$, corresponding to the $\mathrm{C}-\mathrm{O}$ stretching vibration. The band at $620 \mathrm{~cm}^{-1}$ corresponds to the $\mathrm{CO}$ out-of-plane deformation. ${ }^{34}$

Further, we conjugated the HSA-FITC system noncovalently on the surface of oxidized MWCNTs. First, we covalently labeled HSA with FITC at an increased $\mathrm{pH}($ above $\mathrm{pH}=9)$, as shown schematically in Figure IA. ${ }^{35}$ FITC covalently attached to the protein through the alpha-amino group. Second, HSAFITC complex was adsorbed on the nanotubes, presumptively, through electrostatic interactions between the functional groups of MWCNTs and the protein-positive domains (Figure IB). Considering the fact that not all the surface of the nanotubes is oxidized, hydrophobic interactions can also occur. ${ }^{36}$

UV-Vis spectroscopy is a simple but efficacious method that confirms the formation of the oxidized MWCNT-HSAFITC complex. The nanotubes solutions give an adsorption band at $295.7 \mathrm{~cm}^{-1}$, which corresponds to the +-plasmon transition of MWCNT. ${ }^{37}$

The yellowish HSA-FITC solution has the characteristic adsorption band at $489 \mathrm{~cm}^{-1}$ and a second adsorption band at $292 \mathrm{~cm}^{-1}$, suggesting the existence of aromatic amino acids from HSA. Comparing the aforementioned spectra, the formation of the MWCNTs-HSA-FITC complex becomes obvious due to the appearance of the oxidized MWNT band and the HSA-FITC band at $475.6 \mathrm{~cm}^{-1}$, which is shifted and has low intensity (Figure 2C).
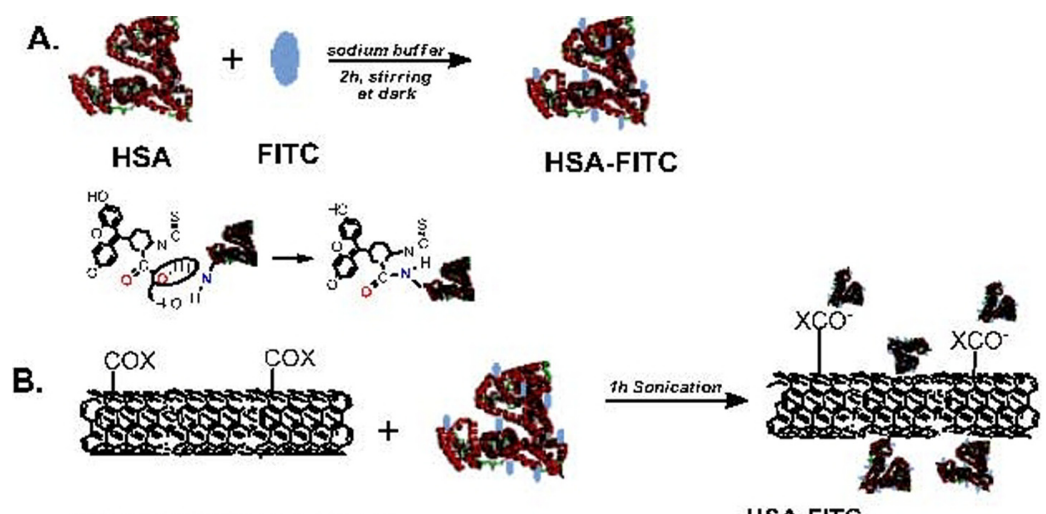

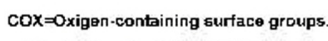

Oxidized-MWCNTs

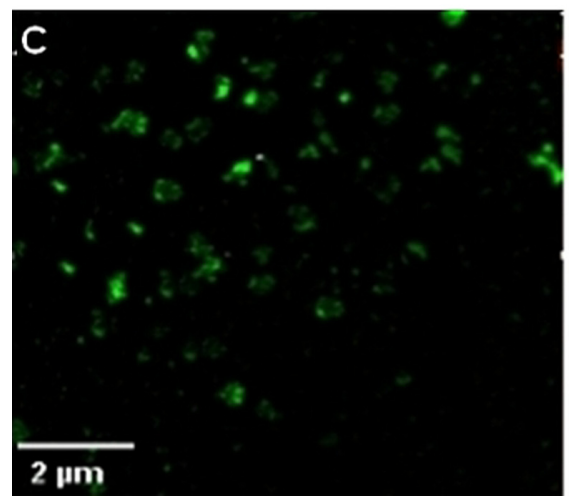

HSA-FITC

HSA-FITC

Oxidized MWCNTS-HSA-FITC

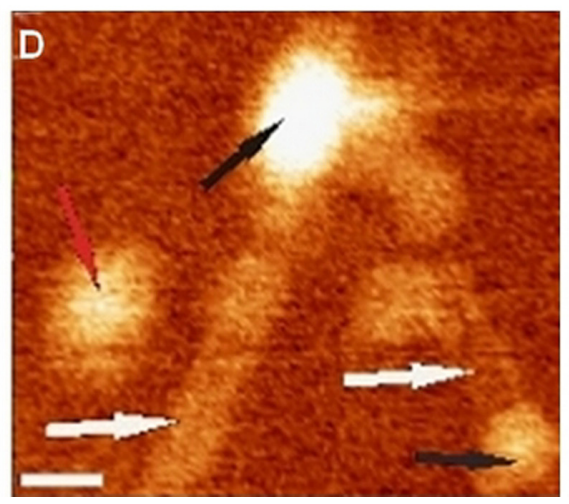

Figure I A) Illustration of the covalent labeling of HSA with FITC. B) The formation of oxidized MWCNTs-HSA-FITC. C) A typical fluorescent image of HSA-MWCNTs (100 mg/L): globular fluorescent CNTs corresponding to attached large molecules of fluorescent albumin are being observed. D) I40 $\times$ I $20 \mathrm{~nm}$ AFM topographic image of HSA (black arrows) conjugated with MWCNTs (white arrows). The red arrow indicates the presence of an unconjugated HSA molecule. The scale bar represents 20 nm (bottom-right panel).

Abbreviations: AFM, atomic force microscopy; FITC, fluorescein isothiocyanate; HSA, human serum albumin; MWCNTs, multiwalled carbon nanotubes. 

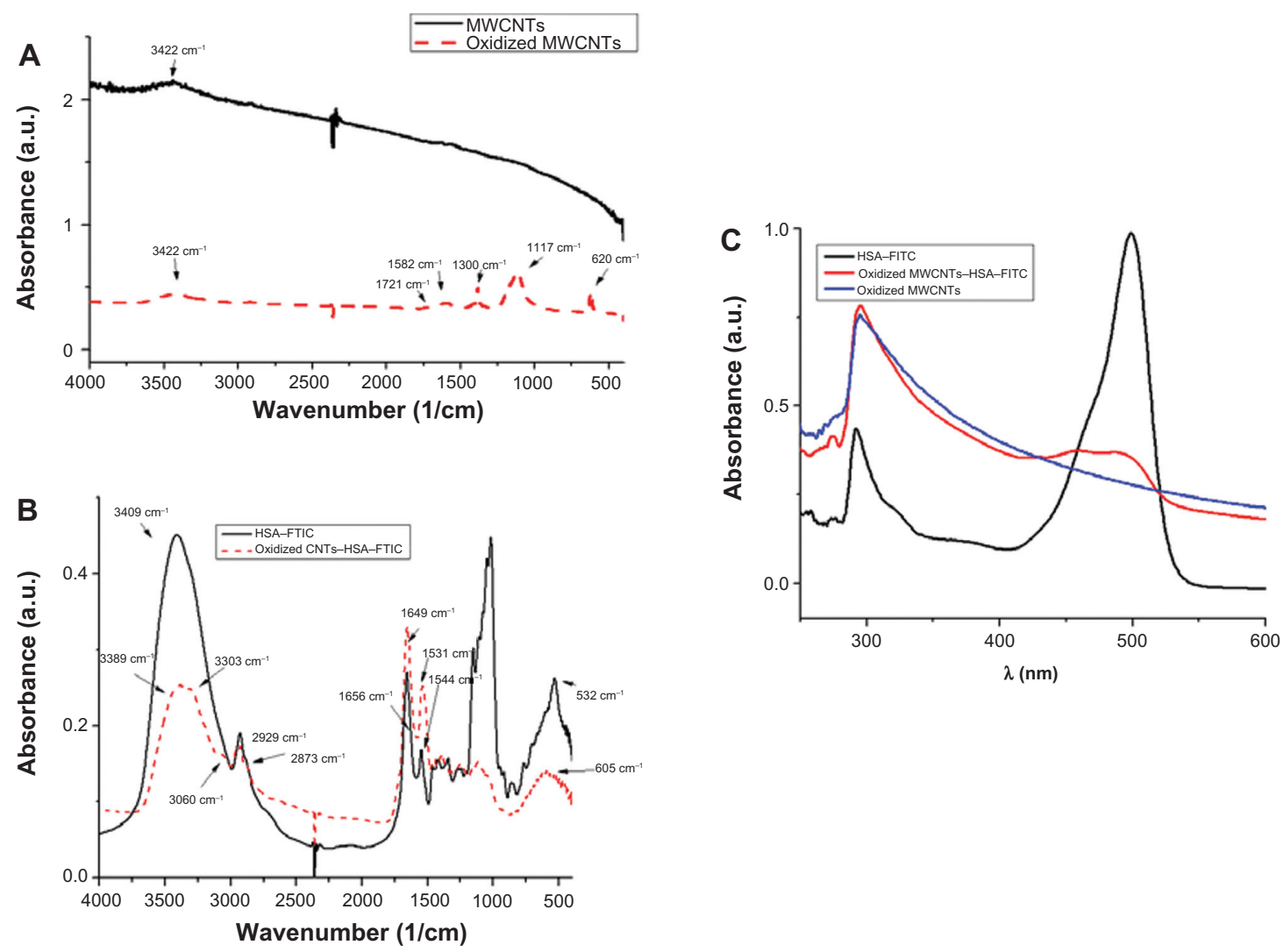

Figure 2 FTIR spectra of A) pristine MWCNTs (black) and oxidized MWCNTs (red); B) HSA-FITC (black) and HSA-FITC-coated oxidized MWCNTs (red); C) UV-Vis adsorption spectra of HSA-FITC (black), oxidized MWCNTs (blue), oxidized MWCNTs-HSA-FITC (red).

Abbreviations: FITC, fluorescein isothiocyanate; FTIR, Fourier transform infrared; HSA, human serum albumin; MWCNTs, multiwalled carbon nanotubes.

The conjugation of HSA-FITC onto the surface of the nanotubes is also confirmed by FTIR spectroscopy as seen in Figure 2B. No similarity can be observed when comparing the spectra of HSA-FITC with those of the nanotube-conjugated HSA-FITC. All the corresponding peaks had shifted their position, and some even disappeared. In the higher region, the stretching vibration band of the $\mathrm{N}-\mathrm{H}$ groups at $3409 \mathrm{~cm}^{-1}$ changed their shape in a broad band that included two peaks: one at $3389 \mathrm{~cm}^{-1}(\mathrm{~N}-\mathrm{H}$ groups stretching vibration) and the second at $3303 \mathrm{~cm}^{-1}$, which is the pyridine aromatic $\mathrm{C}-\mathrm{H}$ vibrations band. The aliphatic $\mathrm{C}-\mathrm{H}$ stretching vibration at 2929 and $2873 \mathrm{~cm}^{-1}$ moved at 2922 and $2865 \mathrm{~cm}^{-1}$, such that these groups were involved in electrostatic bonds. In addition, the amide I and II are shifted to low frequency: amide I, from 1656 to $1649 \mathrm{~cm}^{-1}$; amide II, from 1544 to $1532 \mathrm{~cm}^{-1}$. The asymmetric and symmetric deformations of $\mathrm{CH}_{3}$ have changed their bands from 1459 to $1447 \mathrm{~cm}^{-1}$ and $1416-1389 \mathrm{~cm}^{-1}$, respectively. The region in between has dramatically changed their intensity. This is due to the spontaneous adsorption of the crystalline HSA-FITC complex on the MWCNTs and the formation of a well-organized oxidized MWCNT-HSA-FITC.
To that end, atomic force microscopy (AFM) analysis of the HSA-MWCNTs solution was performed. Representative AFM evidence of the successful attachment of HSA molecules onto the surface of the nanotubes is shown in Figure ID. By AFM, analysis at the nanometric scale of the two HSA molecules (black arrows in Figure ID) attached at the end of the nanotubes (white arrows) was carried out. A single HSA molecule (red arrow) has also been observed in the topographic image shown here. The length of the CNTs was estimated as being $<200 \mathrm{~nm}$. The lateral resolution of an AFM image is determined by the tip of the object that is imaged. In the presented image, the width of the nanotube appears to be $>2 \mathrm{~nm}$, as we used an AFM tip with a $\sim 15 \mathrm{~nm}$ radius of curvature.

\section{HSA-MWCNT internalization}

The ability of an FITC-labeled bioconjugate of HSAMWCNTs to internalize inside an HepG2 cell was evaluated by confocal fluorescence microscopy imaging. The results presented in Figure 3B show that at low concentration and short exposure time, HSA-MWCNT accumulates inside HepG2 cells. Thus, we provided imaging evidence that HSA can act as a carrier for MWCNTs, and because we 
were unable to identify any fluorescence in the epithelial cells in similar conditions (Figure 3A) we reasoned that HSA-MWCNT bioconjugates exhibit specific affinity for liver cancer cells.

Furthermore, phase contrast microscopy was used to demonstrate the presence of CNTs inside HepG2 cells following HSA-MWCNT administration. As seen in Figure 3E (red arrows), intracellular aggregates of MWCNTs appear as dark, optically dense signals that associate with a refringent signal under phase contrast. Once more, we were unable to identify any aggregates inside the epithelial cells that have been similarly treated. (Figure 3D) Moreover, the cellular areas that appeared to contain MWCNTs were further subjected to TEM analysis. When these regions were observed under TEM, MWCNTs could be clearly identified in the form of intracellular aggregates, as shown by the red arrows in Figure $3 \mathrm{~F}$.

\section{The mechanism of selective internalization of HSA-MWCNTs inside the malignant liver cells}

In order to shed light on the molecular mechanisms involved in the specific uptake of HSA-MWCNTs in HepG2 cells, we investigated the possibility that a $60 \mathrm{kDa}$ glycoprotein, Gp60, which is known to function in albumin transcytosis in malignant cells, ${ }^{38}$ was involved in the selective uptake of albumin bound to CNTs. To accomplish this, we allowed the cells treated with $5 \mathrm{mg} / \mathrm{L}$ HSA-MWCNTs for $1 \mathrm{~h}$ to incorporate cy3-anti-Gp60 Ab for $30 \mathrm{~min}$ at $37^{\circ} \mathrm{C}$. To that end, we obtained fluorescent images demonstrating the internalized cy3 fluorescence (Figure 4A, first panel).

Also, we showed that HepG2 cells internalized with albumin-bound MWCNTs (fluorescently labeled with FITC) were distributed into the punctate structure inside the cells (Figure 4A, 2nd panel). DAPI, which is known to form fluorescent complexes with natural double-stranded DNA, was used for nuclei staining. In Figure 4A, fourth panel, nearly complete colocalization of the FITC fluorescence (green image) and cy3 fluorescence (red image) was evident by yellow in the merged image. This finding suggests that albumin bound to MWCNTs was incorporated into plasmalemmal vesicles containing Gp60 as a membrane protein, further validating HSA-MWCNT specificity for Gp60 receptors. Importantly, as seen in Figure 4B, no significant colocalization in the hepatocyte cells (CRL-4020) was observed for
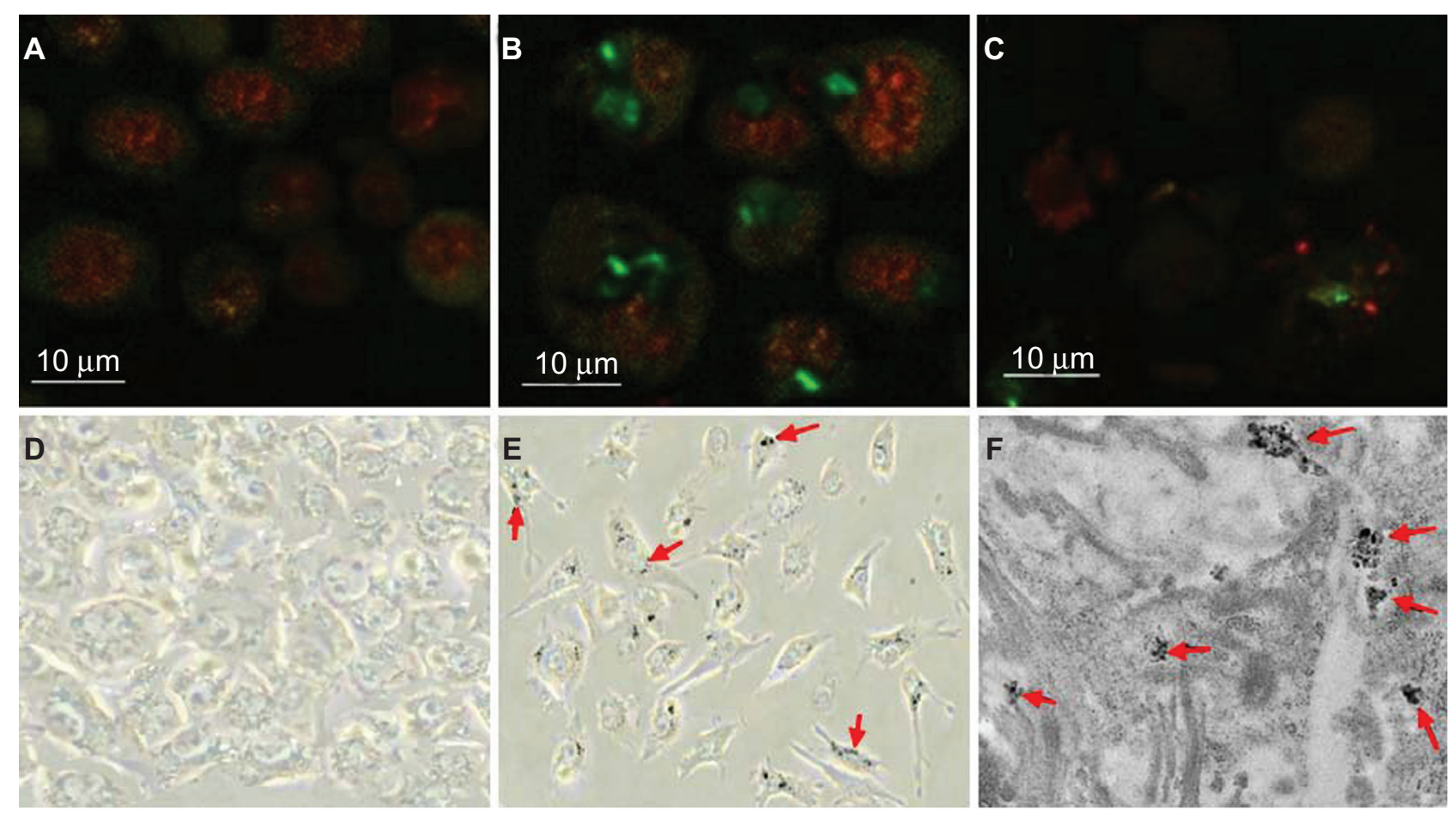

Figure 3 Selective nanophotothermolysis of HepG2 cells. A) Confocal image of human hepatocytes incubated for 30 min with 5 mg/L FITC-HSA-MWCNTs. (The nucleus was stained with DRAQ5-red.) B) Confocal detection of MWCNT-HSA-FITC (green) selectively internalized into HepG2 cells (exposed for 30 min to 5 mg/L of FITC-HSAMWCNTs). C) HepG2 cells were irradiated for 2 min using a 2-W, 808-nm laser beam. Image of cell lysate and aggregated cells after internalization of MWCNT-HSA-FITC and laser radiation. D) CRL-4020 cells incubated for $30 \mathrm{~min}$ with $5 \mathrm{mg} / \mathrm{L}$ FITC-HSA-MWCNTs visualized by phase contrast microscopy ( $\times 400$ magnification). E) HepG 2 cells incubated for 30 min with $5 \mathrm{mg} / \mathrm{L}$ FITC-HSA-MWCNTs visualized by phase contrast microscopy ( $\times 400$ magnification). F) Transmission electron microphotograph showing clusters of MWCNTs surrounded by plasmalemmal vesicles, confirming the presence of nanomaterial inside the cell $(\times 24,000$ magnification). Abbreviations: FITC, fluorescein isothiocyanate; HSA, human serum albumin; MWCNTs, multiwalled carbon nanotubes. 

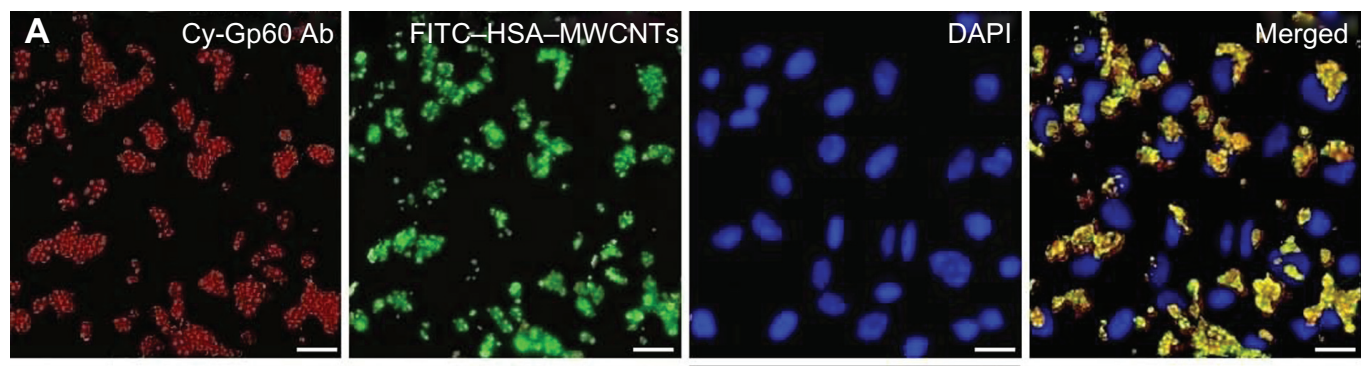

HepG2
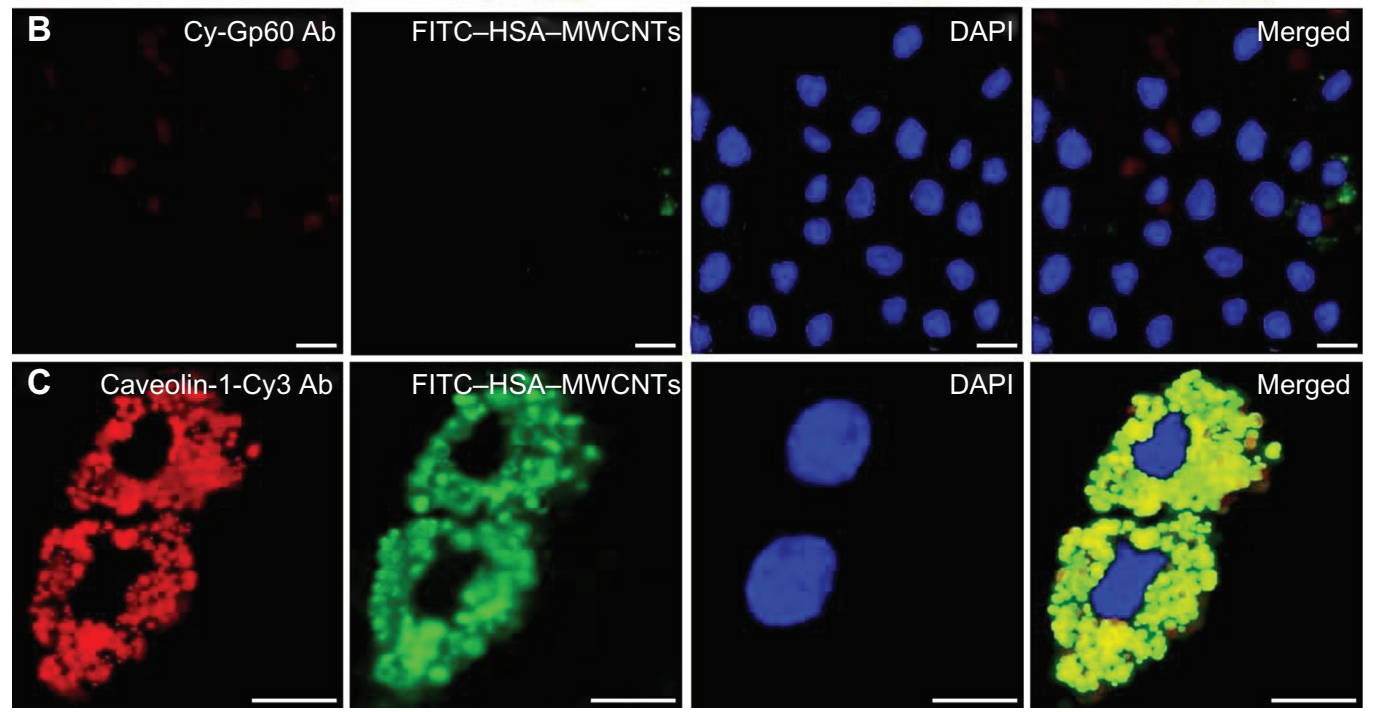

CRL-4020

Figure 4 HSA-MWCNTs in vitro endocytosis mechanism in human liver cancer cells. A) Colocalization of Cy-Gp60 antibody and FITC-HSA-MWCNTs in HepG2 cells. B) Colocalization of Cy-Gp60 antibody and FITC-HSA-MWCNTs in hepatocyte epithelial cells. C) Colocalization of caveolin-I-Cy antibody and FITC-HSA-MWCNTs in HepG2 cells. Results are representative of three experiments. Scale bar: $20 \mu \mathrm{m}$ in all panels.

Abbreviations: DAPI, 4'-6-diamidino-2-phenylindole; FITC, fluorescein isothiocyanate; HSA, human serum albumin; MWCNTs, multiwalled carbon nanotubes.

cy3-Gp60 Ab and HSA-FITC-MWCNTs incubated under same circumstances.

Therefore, based on these data, we showed that HSAMWCNTs can act as specific and sensitive site-targeted nanosystems against Gp60 receptor located on the liver cancer cell membrane.

\section{Association of caveolin-I with FITC-HSA-MWCNTs-containing vesicles}

Most data indicate that caveolae-mediated endocytosis in cells is stimulated by the binding of albumin to Gp60, a receptor located in the caveolae..$^{38}$

Given these data and the described role of caveolin in albumin endocytosis, we reasoned that the mechanism of HSA-MWCNT internalization in HepG2 cells was similar. To test this hypothesis, we immunostained the HepG2 cells with Cy3-anti-caveolin-1 Ab. As shown in Figure 4C, confocal imaging revealed that the majority of FITC-HSA-MWCNTcontaining plasmalemmal vesicles stained for caveolin-1 used this fluorescent anti-caveolin-1 monoclonal Ab. Taken together, all these data demonstrate that HSA-MWCNTs selectively internalize in human hepatocellular cancer cells via caveolae-mediated endocytosis by the binding of the albumin carrier to Gp60, a specific albumin-binding protein.

\section{Cytotoxicity induced by laser irradiation or by the administration of HSA-MWCNTs}

Before testing the in vitro response of HSA-MWCNT-treated cells to laser irradiation, we investigated the possible effect of cytotoxicity induced by the administration of CNTs in the cells. HepG2 cells and the epithelial cells were treated with various concentrations of HSA-MWCNT at various incubation periods. Cell Death Detection ELISA ${ }^{\text {PLUS }}$ was used to evaluate the effect of MWCNT bioconjugates on cell viability.

After $24 \mathrm{~h}$ of incubation, HepG2 exposed to $50 \mathrm{mg} / \mathrm{L}$ of HSA-MWCNT showed a $5.71 \%$ decrease in viability compared with $1.6 \%(P<0.02)$ (Table I). For human hepatocytes exposed to $50 \mathrm{mg} / \mathrm{L}$ of HSA-MWCNT, the decrease in viability was $6.23 \%$ compared with the nontreated sample, in which the percentage of viable cells was $98.7 \%(P<0.001)$. 
Table I Cytotoxic-induced effects on HepG2 and CRL-4020 cells by various concentrations of bionanomaterial at various incubation times

\begin{tabular}{|c|c|c|c|c|c|c|}
\hline \multirow[t]{2}{*}{$\begin{array}{l}\text { HSA-MWCNTs } \\
\text { concentration }\end{array}$} & \multicolumn{6}{|c|}{$\begin{array}{l}\text { Cytotoxicity effects at different incubation } \\
\text { intervals (\%) }\end{array}$} \\
\hline & $I \mathrm{~min}$ & $30 \mathrm{~min}$ & I h & $3 \mathrm{~h}$ & $5 \mathrm{~h}$ & $24 \mathrm{~h}$ \\
\hline CRL-4020 control & 0 & 0.2 & 0.3 & 0.4 & 0.9 & 1.6 \\
\hline HepG2 control & 0 & 0.1 & 0.3 & 0.5 & I.I & 1.3 \\
\hline CRL-4020 I mg/L & 0.3 & 0.5 & 0.7 & 1.9 & 2.4 & 3.8 \\
\hline HepG2 I mg/L & 0.5 & 0.8 & 0.9 & 2.2 & 2.5 & 3.6 \\
\hline CRL-4020 5 mg/L & 0.6 & 0.9 & 1 & 2.4 & 3.1 & 4.2 \\
\hline HepG2 5 mg/L & 0.4 & 0.7 & 0.8 & 2.6 & 3.2 & 4.4 \\
\hline CRL-4020 20 mg/L & 0.7 & 0.8 & 1.2 & 3 & 3.1 & 4.8 \\
\hline HepG2 20 mg/L & 0.8 & 1.2 & 1.2 & 2.6 & 2.8 & 4.5 \\
\hline CRL-4020 $50 \mathrm{mg} / \mathrm{L}$ & 0.6 & 0.8 & 1.8 & 2.2 & 2.8 & 4.9 \\
\hline HepG2 50 mg/L & $\mathrm{I} .4$ & 1.5 & 1.6 & 2.2 & 2.8 & 6.2 \\
\hline
\end{tabular}

Abbreviations: HSA, human serum albumin; MWCNTs, multiwalled carbon nanotubes.

The statistical data showed that nanomaterial exposure per se induced no significant cytotoxic effects at small and medium concentrations ( $P>0.05$ for all comparisons).

The next step in order to eliminate any potential errors was represented by a 2 minutes irradiation of a sample of cells without nanoparticles, using a $2 \mathrm{~W}, 808 \mathrm{~nm}$ laser beam. There was no lysis among the cells after irradiation. The process demonstrates the transparency of HepG2 for NIR beam.

\section{Assessment of cellular necrosis after laser treatment and administration of HSA-MWCNTs}

The postirradiation lysis rate of HepG2 cells treated with HSA-MWCNTs ranged from $35.45 \%$ (for $1 \mathrm{mg} / \mathrm{L}$ ) to $88.24 \%$ (for $50 \mathrm{mg} / \mathrm{L}$ ) at $60 \mathrm{sec}(P<0.001)$, whereas at $30 \mathrm{~min}$ the necrotic rate increased from $59.34 \%(1 \mathrm{mg} / \mathrm{L})$ to $92.34 \%$ (50 mg/L), $P$ value $<0.001$. Significantly lower apoptotic rates were obtained in irradiated epithelial cells treated for $60 \mathrm{sec}$ and $30 \mathrm{~min}$ at concentrations ranging from $1 \mathrm{mg} / \mathrm{L}$ to $50 \mathrm{mg} / \mathrm{L}(6.78 \%-64.32 \%$ for $60 \mathrm{sec} ; 9.89 \%-70.78 \%$ for $30 \mathrm{~min}$ ). As can be observed, the optimal apoptotic effect of malignant cells after incubation with HSA-MWCNT was obtained at a concentration of $5 \mathrm{mg} / \mathrm{L}$ (HepG2/CRL-4020: $65.79 \% / 11.34 \%$ at $60 \mathrm{sec}$, and $75.34 \% / 14.67 \%$ at $30 \mathrm{~min}$ ) (Figure 5). After $60 \mathrm{~min}$ of incubation, the difference among the apoptotic rates was also statistically significant among the two cell lines for low/medium concentrations of HSAMWCNT (78.92\%: $1 \mathrm{mg} / \mathrm{L}, 88.34 \%$ : $5 \mathrm{mg} / \mathrm{L}, 87.88 \%$ : $20 \mathrm{mg} / \mathrm{L}$, for HepG2; 15.56\%: $1 \mathrm{mg} / \mathrm{L}, 21.34 \%: 5 \mathrm{mg} / \mathrm{L}$, 52.14\%: $20 \mathrm{mg} / \mathrm{L}$, for CRL-4020). $P$ values were $<0.001$ for comparisons between various forms of nanomaterials.
No significant differences $(P=0.143)$ among the apoptotic rates of HepG2 and CRL-4020 treated with HSA-MWCNT could be observed (100\%: HepG2; 84.13\%: CRL-4020) for a high concentration of nanomaterials $(50 \mathrm{mg} / \mathrm{L})$.

After 3-5 h of incubation, a significant apoptotic rate of the two cell lines was obtained only when the cells were treated with low concentrations of nanomaterials $(<20 \mathrm{mg} / \mathrm{L})$. Elevated concentrations recorded a nonsignificant difference in the cell lysis effect of the two cell lines $(P=0.256-20 \mathrm{mg} / \mathrm{L} ; P=0.296-50 \mathrm{mg} / \mathrm{L})$.

After $24 \mathrm{~h}$ of incubation, the HepG2 cells treated with $1 \mathrm{mg} / \mathrm{L}$ HSA-MWCNT were $100 \%$ necrotic after laser irradiation, as compared with $52.2 \%$ of the CRL- 4020 cells similarly treated. For very low concentrations of HSA-MWCNTs, we could observe a difference among the percentage of dead cells of the two cell lines. However, the difference reached only a marginal significance $(P=0.07)$. The lysis rate of the irradiated cells incubated with more than $5 \mathrm{mg} / \mathrm{L}$ nanomaterials for $24 \mathrm{~h}$ was almost similar for the two cell lines (100\% vs 85.94\%).

In contrast, no significant differences in the percentage of nonviable cells were obtained between the two cell lines when the nonfunctionalized MWCNT solution was used for treatment $(P>0.05$ for all comparison and each exposure interval). Moreover, for HepG2 cells, the results showed a significant difference between MWCNTs and MWCNTHSA-exposed groups for low concentrations (1, 5, and $20 \mathrm{mg} / \mathrm{L}$ ) and short exposures (60 sec, $30 \mathrm{~min}, 1 \mathrm{~h}, 3 \mathrm{~h}$, and 5 h) (Figure 5).

\section{Discussion}

The main goal of this investigation was to develop and test a new method of treatment of human HCC. Preliminary data from literature support the involvement of albumin in tumor growth. The implication is supported by the fact that albumin enhances tumor expansion, as it is used for synthesis in various cellular compartments. ${ }^{38}$

In order to investigate the toxicity effects of the nanoconjugates, HepG2 cells and CRL-4020 epithelial cells were exposed and incubated with HSA-MWCNTs at various concentrations and incubation times. Consistent with other findings, we demonstrate that only high concentrations of MWCNT bioconjugates exhibit cytotoxic effects. ${ }^{31}$ Nevertheless, the toxicity, which represents a major obstacle in using CNTs in clinical applications, may be minimized by administration of low doses of nanoconjugates. ${ }^{9,13,23}$

Further, we used HSA-MWCNTs as heat-inducing agents under laser radiation during the process of 

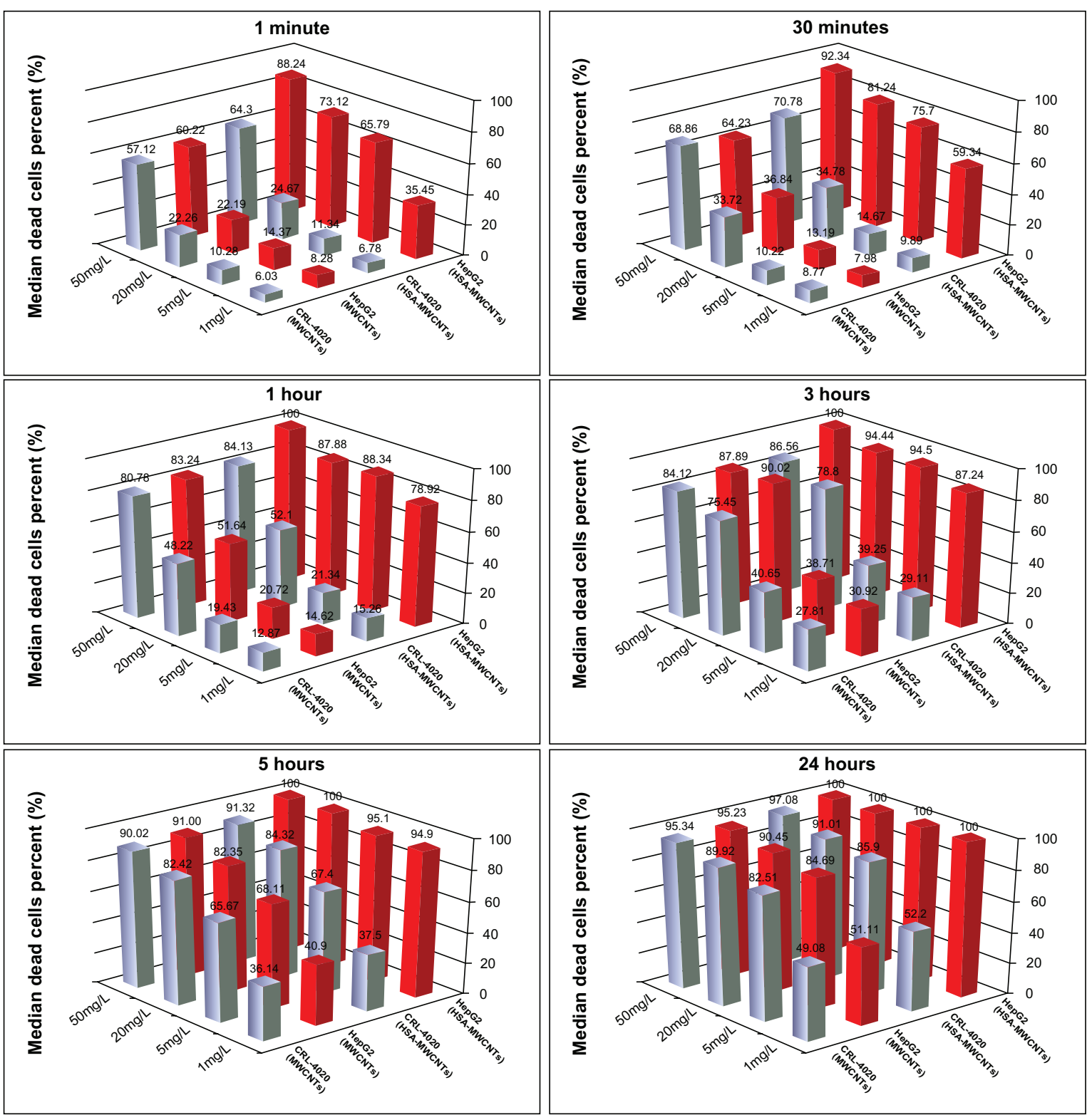

Figure 5 Results of experimental seriate exposure to nanomaterials (control vs MWCNTs-HSA) in different concentrations, followed by laser irradiation. Bars represent the average percentage of dead cells (\%).

Abbreviations: HSA, human serum albumin; MWCNTs, multiwalled carbon nanotubes.

nanophotothermolysis. This method is based on the presence and clustering of HSA-MWCNTs inside the cells and their highly optical absorption capabilities responsible for inducing thermal effects, especially under NIR irradiation, where the biological systems have low absorption and high transparency. ${ }^{10,19-22,39,40}$ The optoelectronic transitions in the graphitic structures of the MWCNTs clusters generate thermal energy ${ }^{41}$ that rapidly diffuses into the subcellular compartments, where the nanoconjugates are present.

Laser-induced thermal ablation of cancer cells labeled with HSA-MWCNTs may be used in two main modes: pulsed and continuous. The pulsed mode produces localized (few micrometers) damage of individual cancer cells by laser-induced micro- and nanobubbles around overheated nanoparticles without harmful effects on the surrounding healthy cells. ${ }^{42}$ It particularly favors in vivo killing of single circulating tumor cells using just $1 \mathrm{~ns}$ laser pulses. The second mode is more time consuming (a few minutes of exposure) and results in the effects of thermal denaturation and coagulation as main mechanisms of cell damage. It is more appropriate for the treatment of primary tumors measuring a few millimeters or more. ${ }^{42}$ 
The use of continuous laser irradiation proved significant differences in HepG2 postirradiation apoptotic percentage $(P<0.05)$ for concentrations of $<20 \mathrm{mg} / \mathrm{L}$, at $60 \mathrm{sec}$ and $30 \mathrm{~min}$, compared with the apoptotic rate of CRL-4020. This finding may be particularly relevant for low concentrations of HSA-MWCNTs (eg, plasma levels after intra-arterial administration). ${ }^{43}$ It has been previously stated that the mechanism of HepG2 uptake for albumin is a caveolae-dependent endocytosis similar to that for other types of ligands such as cholesterol or folic acid. ${ }^{44}$ The mechanism represents a distinct form of transport and elicits features different from independent or clathrin-mediated endocytosis. After internalization of caveolae, the biomaterials are accumulated in caveosomes, a specific type of organelles. ${ }^{45}$ Folic acid has been intensely studied for its potential in targeted therapies. Significant results were obtained after binding folate-functionalized poly (ethylene glycol)-coated nanoparticles to the targeted receptor (folate receptor). ${ }^{46}$ Within the field of chemotherapy, caveolae-mediated transport mechanisms have been largely used for targeted drug delivery. The pathway has been preferred as it was demonstrated to be a nondegradative mechanism using $\mathrm{pH}$-dependent chemotherapy release. For instance, a combination of cytostatic drugs and albumin called Trexall ${ }^{\circledR}$ (Duramed Pharmaceuticals, New York, NY, USA) is currently prescribed for the treatment of metastatic liver cancer in humans. ${ }^{47}$ The literature has already suggested new ideas of targeted therapies that could elude lysosomal harmful transit and will therefore offer a higher protection level for drug compounds. ${ }^{48} \mathrm{~A}$ specific endothelin receptor associated with the described uptake mechanism is the Gp60 receptor (albondin). ${ }^{49}$ Using phase contrast, confocal, and TEM, we demonstrated in this study, without precedent, that the mechanism of HSAMWCNT uptake in HepG2 cells occurs through caveolaedependent endocytosis initiated by the albumin-binding Gp60 receptor (albondin) (Figure 4).

In the present study, we observed that in the treatment of HepG2 cells with high concentrations of HSA-MWCNTs for more than $5 \mathrm{~h}$, the percentage of necrotic HepG2 cells is not significantly different from that of epithelial cells. This finding suggests a nonselective, passive intracellular diffusion of nanomaterial inside the cells when the cells are exposed to high concentrations of nanomaterials for long periods of time.

In contrast, we obtained a selective lysis of HepG2 cells treated with HSA-MWCNTs for incubation periods shorter than $30 \mathrm{~min}$, regardless of the concentration. In cellular systems, the molecular membrane association/dissociation processes are very short, ranging from seconds to minutes. ${ }^{50}$ Therefore, our finding could be of decisive importance when using HSA-MWCNTs for the in vivo targeting of liver cancer cells.

\section{Conclusion}

We have developed a method of functionalization of CNT with human albumin for the selective targeting of liver cancer cells. Moreover, to our knowledge, this is the first evidence of improved selective thermal ablation of liver cancer cells using HSA-MWCNTs compared with the normal epithelial cells. Based on the results presented here, we believe that HSA-MWCNTs selectively attach to albondin (aka Gp60) receptor located on HepG2 cell membrane, followed by uptake through a caveolin-dependent endocytosis process.

These results may represent a first step in the process of complete in vivo elimination of liver cancer cells using nanolocalized thermal ablation by means of laser heating.

However, further research is required in order to fully understand the mechanisms of selective binding of HSAMWCNTs in malignant cells.

Nevertheless, further investigations are also required for the careful assessment of unexpected toxicities and biological interactions of HSA-MWCNTs inside the living organism.

\section{Acknowledgments}

The authors acknowledge grant support from the Romanian Ministry of Research (CNMP-PNCDI II: NANOPAN 41-009 and NANOHEP 42-115). This research was also supported by Romanian Society of Nanomedicine.

\section{Disclosure}

The authors report no conflicts of interest in this work.

\section{References}

1. Wong RJ, Corley DA. Survival differences by race/ethnicity and treatment for localized hepatocellular carcinoma within the United States. Dig Dis Sci. 2009;54(9):2031-2039.

2. Varela M, Bruix J. Hepatocellular carcinoma in the United States. Lessons from a population-based study in Medicare recipients. $J$ Hepatol. 2006;44(1):8-10.

3. Bosch FX, Ribes J, Díaz M, Cléries R. Primary liver cancer: worldwide incidence and trends. Gastroenterology. 2004;127(5 Suppl 1):S5-S16.

4. Kiyosawa K, Umemura T, Ichijo T, et al. Hepatocellular carcinoma: recent trends in Japan. Gastroenterology. 2004;127(5 Suppl 1):S17-S26. 
5. Rampone B, Schiavone B, Martino A, Viviano C, Confuorto G. Current management strategy of hepatocellular carcinoma. World $J$ Gastroenterol. 2009;15(26):3210-3216.

6. Lai EC, Fan ST, Lo CM, Chu KM, Liu CL, Wong J. Hepatic resection for hepatocellular carcinoma. An audit of 343 patients. Ann Surg. 1995; 221(3):291-298.

7. Cance WG, Stewart AK, Menck HR. The National Cancer Data Base Report on treatment patterns for hepatocellular carcinomas: improved survival of surgically resected patients, 1985-1996. Cancer. 2000;88(4): 912-920.

8. Ferrari M. Cancer nanotechnology: opportunities and challenges. Nat Rev Cancer. 2005;5(3):161-171.

9. Chakravarty P, Marches R, Zimmerman NS, et al. Thermal ablation of tumor cells with antibody-functionalized single-walled carbon nanotubes. Proc Natl Acad Sci U S A. 2008;105(25):8697-8702.

10. Liu Z, Tabakman S, Welsher K, Dai H. Carbon nanotubes in biology and medicine: in vitro and in vivo detection, imaging and drug delivery. Nano Res. 2009;2(2):85-120.

11. Liang P, Wang Y. Microwave ablation of hepatocellular carcinoma. Oncology. 2007;72 Suppl 1:S124-S131.

12. Wang ZY, Song J, Zhang DS. Nanosized $\mathrm{As}_{2} \mathrm{O}_{3} / \mathrm{Fe}_{2} \mathrm{O}_{3}$ complexes combined with magnetic fluid hyperthermia selectively target liver cancer cells. World J Gastroenterol. 2009;15(24):2995-3002.

13. Cardinal J, Klune JR, Chory E, et al. Noninvasive radiofrequency ablation of cancer targeted by gold nanoparticles. Surgery. 2008;144(2): $125-132$.

14. Lapotko D, Lukianova E, Potapnev M, Aleinikova O, Oraevsky A. Method of laser activated nano-thermolysis for elimination of tumor cells. Cancer Lett. 2006;239(1):36-45.

15. Welsher K, Liu Z, Daranciang D, Dai H. Selective probing and imaging of cells with single walled carbon nanotubes as near-infrared fluorescent molecules. Nano Lett. 2008;8(2):586-590.

16. Bianco A, Kostarelos K, Partidos CD, Prato M. Biomedical applications of functionalised carbon nanotubes. Chem Commun (Camb). 2005;(5): 571-577.

17. Srinivasan C. Carbon nanotubes in cancer therapy. Curr Sci. 2008; 94(3):300-301.

18. Peer D, Karp JM, Hong S, Farokhzad OC, Margalit R, Langer R. Nanocarriers as an emerging platform for cancer therapy. Nat Nanotechnol. 2007;2(12):751-760.

19. Bhirde AA, Patel V, Gavard J, et al. Targeted killing of cancer cells in vivo and in vitro with EGF-directed carbon nanotube-based drug delivery. ACS Nano. 2009;3(2):307-316.

20. Dumortier H, Lacotte S, Pastorin G, et al. Functionalized carbon nanotubes are non-cytotoxic and preserve the functionality of primary immune cells. Nano Lett. 2006;6(7):1522-1528.

21. Shi Kam NW, Jessop TC, Wender PA, Dai H. Nanotube molecular transporters: internalization of carbon nanotube-protein conjugates into Mammalian cells. J Am Chem Soc. 2004;126(22):6850-6851.

22. Ghosh S, Dutta S, Gomes E, et al. Increased heating efficiency and selective thermal ablation of malignant tissue with DNA-encased multiwalled carbon nanotubes. ACS Nano. 2009;3(9):2667-2673.

23. Schipper ML, Nakayama-Ratchford N, Davis CR, et al. A pilot toxicology study of single-walled carbon nanotubes in a small sample of mice. Nat Nanotechnol. 2008;3(4):216-221.

24. Di Stefano G, Fiume L, Bolondi L, Lanza M, Pariali M, Chieco P. Enhanced uptake of lactosaminated human albumin by rat hepatocarcinomas: implications for an improved chemotherapy of primary liver tumors. Liver Int. 2005;25(4):854-860.

25. Kratz F. Albumin, a versatile carrier in oncology. Int J Clin Pharmacol Ther. 2010;48(7):453-455.

26. Kratz F. Albumin as a drug carrier: design of prodrugs, drug conjugates and nanoparticles. J Control Release. 2008;132(3):171-183.

27. Dennis MS, Jin H, Dugger D, et al. Imaging tumors with an albuminbinding Fab, a novel tumor-targeting agent. Cancer Res. 2007;67(1): 254-261.
28. Tiruppathi C, Finnegan A, Malik AB. Isolation and characterization of a cell surface albumin-binding protein from vascular endothelial cells. Proc Natl Acad Sci U S A. 1996;93(1):250-254.

29. Tiruppathi C, Song W, Bergenfeldt M, Sass P, Malik AB. Gp60 activation mediates albumin transcytosis in endothelial cells by tyrosine kinasedependent pathway. J Biol Chem. 1997;272(41):25968-25975.

30. Heister E, Neves V, Tilmaciu C, et al. Triple functionalisation of singlewalled carbon nanotubes with doxorubicin, a monoclonal antibody, and a fluorescent marker for targeted cancer therapy. Carbon. 2009;47(9): $2152-2160$.

31. Raffa V, Ciofani G, Nitodas S, et al. Can the properties of carbon nanotubes influence their internalization by living cells? Carbon. 2008; 46(12):1600-1610.

32. Suh Y, Afaq F, Khan N, Johnson JJ, Khusro FH, Mukhtar H. Fisetin induces autophagic cell death through suppression of mTOR signaling pathway in prostate cancer cells. Carcinogenesis. 2010;31(8): $1424-1433$.

33. Kovtyukhova NI, Mallouk TE, Pan L, Dickey EC. Individual singlewalled nanotubes and hydrogels made by oxidative exfoliation of carbon nanotube ropes. J Am Chem Soc. 2003;125(32):9761-9769.

34. Socrates G. Infrared and Raman Characteristic Group Frequencies. Tables and Charts. 3rd ed. Chichester (UK): John Wiley \& Sons; 2001.

35. Maeda H, Ishida N, Kawauchi H, Tsujimura K. Reaction of fluorescein-isothiocyanate with proteins and amino acids. I. Covalent and non-covalent binding of fluorescein-isothiocyanate and fluorescein to proteins. J Biochem. 1969;65(5):777-783.

36. Azamian BR, Davis JJ, Coleman KS, Bagshaw CB, Green ML. Bioelectrochemical single-walled carbon nanotubes. $\mathrm{J} \mathrm{Am} \mathrm{Chem} \mathrm{Soc.}$ 2002;124(43):12664-12665.

37. Feng Y, Feng W, Noda H, et al. Photoinduced anisotropic response of azobenzene chromophore functionalized multiwalled carbon nanotubes. J Appl Phys. 2007;102(5):053102-053105.

38. Botos E, Klumperman J, Oorschot V, et al. Caveolin-1 is transported to multi-vesicular bodies after albumin-induced endocytosis of caveolae in HepG2 cells. J Cell Mol Med. 2008;12(5A):1632-1639.

39. Xiao Y, Gao X, Taratula O, et al. Anti-HER2 IgY antibodyfunctionalized single-walled carbon nanotubes for detection and selective destruction of breast cancer cells. BMC Cancer. 2009;9:351.

40. Kam NW, O'Connell M, Wisdom JA, Dai H. Carbon nanotubes as multifunctional biological transporters and near-infrared agents for selective cancer cell destruction. Proc Natl Acad Sci U S A. 2005; 102(33):11600-11605.

41. Dresselhaus MS, Dai H. Carbon nanotubes: continued innovations and challenges. MRS Bull. 2004;29(4):237-243.

42. Zharov VP, Galitovskaya EN, Johnson C, Kelly T. Synergistic enhancement of selective nanophotothermolysis with gold nanoclusters: potential for cancer therapy. Lasers Surg Med. 2005;37(3):219-226.

43. Cherukuri P, Gannon CJ, Leeuw TK, et al. Mammalian pharmacokinetics of carbon nanotubes using intrinsic near-infrared fluorescence. Proc Natl Acad Sci U S A. 2006;103(50):18882-18886.

44. Chang WJ, Rothberg KG, Kamen BA, Anderson RG. Lowering the cholesterol content of MA104 cells inhibits receptor-mediated transport of folate. J Cell Biol. 1992;118(1):63-69.

45. Tiruppathi C, Naqvi T, Wu Y, Vogel SM, Minshall RD, Malik AB. Albumin mediates the transcytosis of myeloperoxidase by means of caveolae in endothelial cells. Proc Natl Acad Sci U SA. 2004;101(20): 7699-7704.

46. Dauty E, Remy JS, Zuber G, Behr JP. Intracellular delivery of nanometric DNA particles via the folate receptor. Bioconjug Chem. 2002; 13(4):831-839.

47. Garber K. Stromal depletion goes on trial in pancreatic cancer. $J$ Natl Cancer Inst. 2010;102(7):448-450.

48. Bathori G, Cervenak L, Karadi I. Caveolae - an alternative endocytotic pathway for targeted drug delivery. Crit Rev Ther Drug Carrier Syst. 2004;21(2):67-95. 
49. Bareford LM, Swaan PW. Endocytic mechanisms for targeted drug delivery. Adv Drug Deliv Rev. 2007;59(8):748-758.
50. Fesce R, Meldolesi J. Peeping at the vesicle kiss. Nat Cell Biol. 1999; 1(1):E3-E4.

International Journal of Nanomedicine

\section{Publish your work in this journal}

The International Journal of Nanomedicine is an international, peerreviewed journal focusing on the application of nanotechnology in diagnostics, therapeutics, and drug delivery systems throughout the biomedical field. This journal is indexed on PubMed Central, MedLine, CAS, SciSearch $®$, Current Contents $® /$ Clinical Medicine,
Journal Citation Reports/Science Edition, EMBase, Scopus and the Elsevier Bibliographic databases. The manuscript management system is completely online and includes a very quick and fair peer-review system, which is all easy to use. Visit http://www.dovepress.com/ testimonials.php to read real quotes from published authors.

Submit your manuscript here: http://www.dovepress.com/international-journal-of-nanomedicine-journal 